\title{
Sternal microcirculation after skeletonized versus pedicled harvesting of the internal thoracic artery: A randomized study
}

Hiroyuki Kamiya, MD, ${ }^{\text {a }}$ Payam Akhyari, MD, ${ }^{\mathrm{a}}$ Andreas Martens, MD, ${ }^{\mathrm{b}}$ Matthias Karck, MD, ${ }^{\mathrm{a}}$ Axel Haverich, MD, ${ }^{\mathrm{b}}$ and Artur Lichtenberg, $\mathrm{MD}^{\mathrm{a}}$

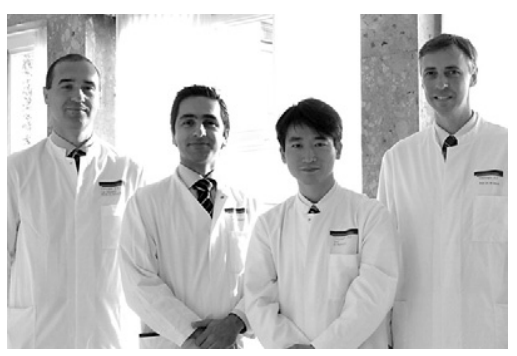

Drs Lichtenberg, Akhyari, Kamiya, and Karck (left to right)
From the Department of Cardiovascular Surgery, ${ }^{\text {a }}$ University of Heidelberg, Heidelberg, Germany; and the Department of Cardiac, Thoracic, Transplantation and Vascular Surgery, ${ }^{\mathrm{b}}$ Hannover Medical School, Hannover, Germany.

Received for publication April 5, 2007; revisions received Aug 29, 2007; accepted for publication Sept 11, 2007.

Address for reprints: Artur Lichtenberg, MD, Department of Cardiac Surgery, University of Heidelberg, Im Neuenheimer Feld 110, 69120 Heidelberg, Germany (E-mail: artur. lichtenberg@med.uni-heidelberg.de).

J Thorac Cardiovasc Surg 2008;135:32-7

$0022-5223 / \$ 34.00$

Copyright (C) 2008 by The American Association for Thoracic Surgery

doi:10.1016/j.jtcvs.2007.09.004
Objective: In human patients the influence of skeletonized internal thoracic artery harvesting on the sternal microcirculation in the perioperative phase has not been well investigated.

Methods: Twenty-four consecutive male patients who were scheduled for isolated coronary artery bypass grafting were prospectively randomized into 2 groups. The left internal thoracic artery was harvested by using the skeletonized technique in group 1, and it was harvested with a pedicle in group 2. Superficial $(2 \mathrm{~mm})$ and deep $(8 \mathrm{~mm})$ tissue oxygen saturation and blood flow were measured presternally and retrosternally in the upper, middle, and lower sternal parts with a novel laser Doppler flowmetric and remission spectroscopic system (Oxygen-to-See; LEA Medizintechnik, Giessen, Germany).

Results: Presternal tissue oxygen saturation deteriorated at the upper and middle sternum, and presternal blood flow deteriorated at all measurement points after internal thoracic artery harvesting in both groups. Skeletonization had no advantage in maintaining presternal microcirculation. Retrosternal microcirculation also deteriorated at all measurement points after internal thoracic artery harvesting in both groups. However, the deterioration of the retrosternal microcirculation was significantly less in group 1 at the middle and lower sternum; values of oxygen saturation to the baseline were $86 \% \pm 3.8 \%$ versus $60 \% \pm 4.3 \%(P=.001)$ at $2-\mathrm{mm}$ depth and $82 \% \pm 4.2 \%$ versus $61 \% \pm 6.1 \%(P=.009)$ at $8-\mathrm{mm}$ depth at the middle sternum and $95 \% \pm 3.2 \%$ versus $78 \% \pm 1.3 \%(P=.001)$ at 2 -mm depth and $94 \% \pm$ $2.2 \%$ versus $78 \% \pm 4.6 \%(P=.004)$ at 8 -mm depth at the lower sternum in groups 1 and 2 , respectively.

Conclusion: The damage of the tissue microcirculation in the middle and lower retrosternal area is significantly less after internal thoracic artery skeletonization compared with that after the pedicled internal thoracic artery harvesting technique.

S everal studies have demonstrated that the use of the left and bilateral internal thoracic artery (ITA) for coronary revascularization was a major risk factor for sternal wound infections, especially after bilateral ITA harvesting. ${ }^{1-3}$ Previous animal and clinical studies have demonstrated that skeletonized ITA harvesting improves the blood supply to the sternum ${ }^{4-6}$ and thus might reduce the incidence of postoperative sternal infections and morbidity, especially in patients with additional risks for sternal wound complications. However, in human subjects the influence of the skeletonized ITA harvesting method on the microcirculation of the sternum in the perioperative phase has not been investigated because of technical difficulties.

A novel laser Doppler flowmetric and remission spectroscopic system (Oxygento-See; LEA Medizintechnik, Giessen, Germany) enables an exact, direct, contin- 


\section{Abbreviations and Acronyms \\ ITA $=$ internal thoracic artery \\ LITA $=$ left internal thoracic artery \\ $\mathrm{SO}_{2}=$ oxygen saturation}

uous, quantitative noninvasive evaluation of real-time parameters of tissue microcirculation in vivo with high time resolution and low costs. ${ }^{7,8}$ The aim of this study was to evaluate the influence of the skeletonized ITA-harvesting technique on the sternal microcirculation compared with the pedicled ITA-harvesting technique in a randomized study cohort.

\section{Materials and Methods}

Twenty-four consecutive male patients who were scheduled for isolated coronary artery bypass grafting were enrolled in the study. The patients were prospectively randomized into 2 groups. In group 1 (12 patients; age, $62.3 \pm 8.4$ years) the left ITA (LITA) was harvested by using the skeletonized technique with mobilizing of the artery only. Group 2 consisted of 12 patients (age, $60.9 \pm$ 7.6) who underwent LITA harvesting with a pedicle that included the tissue around the artery, accompanying veins, and a portion of the parietal pleura. Exclusion criteria in our investigation were diabetes; diseases, deformation, or both of the sternal bone; obesity (body mass index $>30 \mathrm{~kg} / \mathrm{m}^{2}$ ); low ventricular function with an ejection fraction of less than $40 \%$; New York Heart Association class III and IV; dialysis; female sex; and emergency or redo procedures. Only male patients were included in the present study to minimize study variables. The review board of our institute approved this prospective randomized study, and informed consent was obtained from all patients.

Baseline and in-hospital data were collected from each patient. Baseline characteristics included age, body mass index, left ventricular ejection fraction, cardiac risk factors (eg, smoking status), hypertension, and hyperlipidemia. Operative data included ITA harvest time, number of grafts, crossclamp time, and operative time. During intraoperative measurements, the systemic blood pressure was continuously recorded. In the postoperative observation period, intubation time; time to hospital discharge; incidence of deep, superficial, or both sternal wound infections; myocardial infarction; and in-hospital mortality were recorded.

\section{Measurement Protocol}

The median sternotomy was performed in a conventional fashion. Immediately after median sternotomy, the probe was sequentially placed presternally and retrosternally in the upper, middle, and lower sternal part for measurements of superficial $(2 \mathrm{~mm})$ and deep $(8 \mathrm{~mm})$ tissue oxygen saturation $\left(\mathrm{So}_{2}\right)$ and blood flow (Figure 1, A).

For the measurements, the Oxygen-to-See system, a novel laser Doppler flowmetry and remission spectroscopic system (LEA Medizintechnik) was used in this study (Figure 1,B). This equipment enables the measurement of both tissue blood
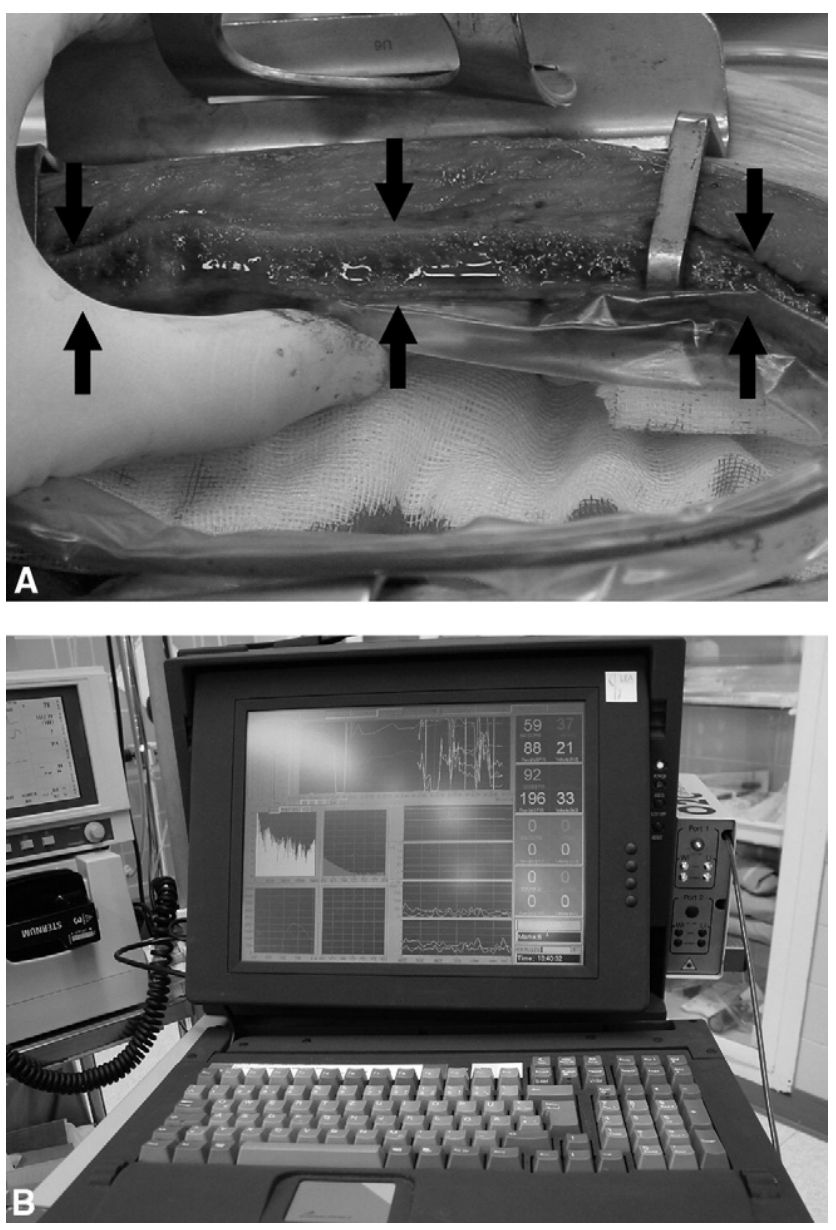

Figure 1. Measurement of microcirculation parameters of the sternum (oxygen saturation and blood flow) at the presternal and retrosternal sides $(A)$ in the upper, middle, and lower parts (arrows) by using a special probe of the laser Doppler flowmetric and remission spectroscopic system (B).

flow by means of laser Doppler spectroscopy and tissue $\mathrm{So}_{2}$ and hemoglobin concentration by means of white-light spectrometric techniques. The mechanism was described in detail in our previous study that used this technique..$^{7,8}$

The LITA was dissected in both groups in full length from its cranial origin to the bifurcation. Side branches were cut by using standard techniques with low-energy electrocautery, titan clipping, or both in both groups. The pedicled LITA was harvested with an approximately 2 -cm-wide pedicle, including the parietal pleura, accompanying veins, and surrounding tissue. In the skeletonized group only the artery was mobilized. Before clamping the distal part of the ITA, the patient received $300 \mathrm{IE}$ heparin $/ \mathrm{kg}$ body weight intravenously.

\section{Statistics}

The data are presented as means \pm standard error of the mean for continuous variables or numbers and percentages for dichot- 
TABLE 1. Baseline characteristics of the patients

\begin{tabular}{lccc}
\hline & $\begin{array}{c}\text { Group 1 } \\
\text { (skeletonized) }\end{array}$ & $\begin{array}{c}\text { Group 2 } \\
\text { (pedicle) }\end{array}$ & $\boldsymbol{P}$ value \\
\hline Age $(\mathrm{y})$ & $62.3 \pm 2.4$ & $60.9 \pm 3.1$ & .651 \\
$\mathrm{BMI}\left(\mathrm{kg} / \mathrm{m}^{2}\right)$ & $24.3 \pm 1.0$ & $23.5 \pm 0.9$ & .723 \\
LVEF $(\%)$ & $55.3 \pm 2.2$ & $59.6 \pm 1.2$ & .467 \\
Risk factors (n) & & & \\
$\quad$ Current smoking & $7 / 12(58 \%)$ & $6 / 12(50 \%)$ & .682 \\
$\quad$ Hypertension & $8 / 12(67 \%)$ & $9 / 12(75 \%)$ & .653 \\
Hyperlipidemia & $7 / 12(58 \%)$ & $8 / 12(67 \%)$ & .682 \\
\hline
\end{tabular}

Data are presented as means \pm standard error of the mean or number of patients. $B M I$, Body mass index; $L V E F$, left ventricular ejection fraction.

omous variables. Univariate analysis of categorical data was carried out by using the $\chi^{2}$ and Fisher exact tests. Changing value of $\mathrm{SO}_{2}$ and blood flow after ITA harvesting to baseline were compared by using paired $t$ tests. Baseline and percentage values of $\mathrm{SO}_{2}$ and blood flow of the 2 groups were compared by using unpaired $t$ tests. The SPSS statistical software package 11.0 for Windows (SPSS, Inc, Chicago, Ill) was used for statistical analysis.

\section{Results}

Demographic data and baseline characteristics of studied patients are listed in Table 1. There were no significant differences between the 2 groups. Table 2 shows the intraoperative and postoperative variables. The harvesting duration was significantly longer in group 1 compared with that in group $2(P=.003)$; however, there were no statistical differences in operative time or postoperative ventilation time. Serious complications did not occur, and length of hospital stay was similar in both groups.

\section{Sternal Tissue $\mathrm{So}_{2}$}

Baseline presternal and retrosternal $\mathrm{So}_{2}$ was measured on the left sternal part, and the results are listed in Table 3. There were no significant differences in baseline values between the 2 groups. After ITA preparation, $\mathrm{SO}_{2}$ decreased significantly at the presternal side in both groups, except for the lower sternum. At the retrosternal side, the decrease of $\mathrm{So}_{2}$ in group 1 at the middle sternal part was significant in both depths and at the lower sternum only at the $8-\mathrm{mm}$ measurement point. On the other hand, the $\mathrm{So}_{2}$ parameters at the retrosternal side in both depths decreased significantly at any measurement point in group 2 .

Percentage value of $\mathrm{So}_{2}$ to the baseline value was compared at each measurement point, and the results are demonstrated in Figures 2 and 3. At the presternal side, there was no difference between the 2 groups at any measurement point. At the retrosternal side, however, the decrease in $\mathrm{So}_{2}$ was not significant at the upper sternum in both groups and significantly greater at the middle and lower sternum in group 2 than it was in group 1.
TABLE 2. Operative and hospital stay characteristics of the patients

\begin{tabular}{lccc}
\hline & $\begin{array}{c}\text { Group 1 } \\
\text { (skeletonized) }\end{array}$ & $\begin{array}{c}\text { Group 2 } \\
\text { (pedicle) }\end{array}$ & $\boldsymbol{P}$ value \\
\hline ITA harvest time (min) & $22 \pm 2.0$ & $13.6 \pm 1.5$ & .003 \\
Operation time (min) & $168 \pm 6.7$ & $176 \pm 5.4$ & .363 \\
Intubation time (h) & $11.5 \pm 2.1$ & $10.3 \pm 2.1$ & .526 \\
Hospital stay (d) & $10.5 \pm 1.3$ & $9.8 \pm 1.7$ & .741 \\
Wound dehiscence & & & \\
$\quad$ or infection & 0 & 0 & .999 \\
$\quad$ Deep & 0 & 0 & .999 \\
$\quad$ Superficial & 0 & 0 & .999 \\
Myocardial infarction & 0 & 0 & .999 \\
Stroke & 0 & 0 & .999 \\
Mortality & & & \\
\hline
\end{tabular}

Data are presented as means \pm standard error of the mean or number of patients. ITA, Internal thoracic artery.

\section{Sternal Blood Flow}

The sternal blood flow significantly decreased at both sides in both groups (Table 4). The percentage value of post-ITA harvest sternal blood flow to the baseline value is demonstrated in Figures 4 and 5. At the presternal side, there was no difference between the 2 groups at any measurement point, except for the 8-mm depth presternally at the upper sternum. At the retrosternal side, however, the decrease of sternal blood flow was significantly greater at the middle and lower sternum in group 2 than it was in group 1, as similar to $\mathrm{So}_{2}$ measurements.

\section{Discussion}

The crucial findings of our study are as follows. First, presternal tissue $\mathrm{SO}_{2}$ deteriorated at the upper and middle sternum, and presternal blood flow deteriorated at all measurement points after ITA harvesting with both techniques (skeletonized and pedicled). Skeletonization had no advantage in maintaining presternal microcirculation. Second, retrosternal microcirculation deteriorated at all measurement points after ITA harvesting with both techniques. However, the deterioration of the retrosternal microcirculation was significantly less with the skeletonized ITA at the middle and lower sternum.

The use of the LITA for coronary revascularization has been recognized as mandatory because of its excellent longterm graft patency, ${ }^{9}$ and the use of both ITAs has been suggested to have an advantage in terms of patient longterm survival over the single-ITA strategy. ${ }^{10}$ However, it has also been well known that the use of double ITAs can worsen the sternal microcirculation and therefore cause postoperative mediastinitis with a significantly higher rate compared with that seen with the single ITA strategy. ${ }^{1-3}$ Some study groups have advocated that the risk of postoperative mediastinitis after the use of double ITAs can be 


\begin{tabular}{|c|c|c|c|c|c|c|}
\hline & \multicolumn{3}{|c|}{ Group 1 (skeletonized) } & \multicolumn{3}{|c|}{ Group 2 (pedicle) } \\
\hline & $\begin{array}{c}\text { Before } \\
\text { harvesting }\end{array}$ & $\begin{array}{c}\text { After } \\
\text { harvesting }\end{array}$ & $P$ value & $\begin{array}{c}\text { Before } \\
\text { harvesting }\end{array}$ & $\begin{array}{c}\text { After } \\
\text { harvesting }\end{array}$ & $P$ value \\
\hline \multicolumn{7}{|l|}{ Presternal } \\
\hline Upper sternal part, 2 mm & $95 \pm 2$ & $79 \pm 2.4$ & .001 & $92 \pm 2.1$ & $78 \pm 4.0$ & .005 \\
\hline Upper sternal part, $8 \mathrm{~mm}$ & $92 \pm 1.4$ & $81 \pm 2.5$ & .001 & $90 \pm 1.8$ & $77 \pm 3.3$ & .003 \\
\hline Middle sternal part, $2 \mathrm{~mm}$ & $86 \pm 1.1$ & $75 \pm 2.3$ & .001 & $90 \pm 2.1$ & $71 \pm 2.6$ & .001 \\
\hline Middle sternal part, $8 \mathrm{~mm}$ & $85 \pm 2.7$ & $71 \pm 5.5$ & .038 & $83 \pm 2.6$ & $70 \pm 2.2$ & .001 \\
\hline Lower sternal part, 2 mm & $80 \pm 4.7$ & $74 \pm 2.1$ & .182 & $76 \pm 3.7$ & $71 \pm 2.4$ & .132 \\
\hline Lower sternal part, 8 mm & $75 \pm 3.9$ & $76 \pm 2.0$ & .769 & $71 \pm 2.9$ & $72 \pm 2.5$ & .872 \\
\hline \multicolumn{7}{|l|}{ Retrosternal } \\
\hline Upper sternal part, 2 mm & $83 \pm 4.6$ & $74 \pm 1.9$ & .103 & $87 \pm 2.9$ & $75 \pm 1.5$ & .005 \\
\hline Upper sternal part, 8 mm & $85 \pm 2.2$ & $78 \pm 2.0$ & .061 & $86 \pm 2.0$ & $73 \pm 2.0$ & .003 \\
\hline Middle sternal part, $2 \mathrm{~mm}$ & $93 \pm 1.0$ & $80 \pm 3.3$ & .005 & $94 \pm 1.4$ & $56 \pm 4.0$ & .001 \\
\hline Middle sternal part, $8 \mathrm{~mm}$ & $89 \pm 1.0$ & $73 \pm 3.5$ & .002 & $89 \pm 1.4$ & $55 \pm 5.4$ & .001 \\
\hline Lower sternal part, 2 mm & $83 \pm 2.9$ & $78 \pm 2.3$ & .099 & $90 \pm 2.4$ & $70 \pm 1.8$ & .001 \\
\hline Lower sternal part, 8 mm & $86 \pm 1.7$ & $81 \pm 1.8$ & .023 & $90 \pm 1.9$ & $69 \pm 3.6$ & .001 \\
\hline
\end{tabular}

Data of oxygen saturation in percentages are presented as means \pm standard error of the mean.

minimized with the skeletonized harvesting technique because it has a great advantage in the preservation of the sternal microcirculation over conventional pedicle techniques. ${ }^{11-13}$ Nevertheless, the influence of ITA-harvesting techniques on sternal microcirculation in human subjects has not been studied enough because of absence of adequate measurement methods in the past.

In a canine model, Parish and colleagues ${ }^{6}$ demonstrated that a minimized retrosternal tissue mobilization by means of skeletonized harvesting of the ITA was associated with a significantly greater residual retrosternal blood flow compared with that of the conventional pedicle preparation technique performed on the corresponding ITA on the other side. Moreover, Fokin and associates ${ }^{14}$ investigated sternal microcirculation with a thermographic camera in a swine

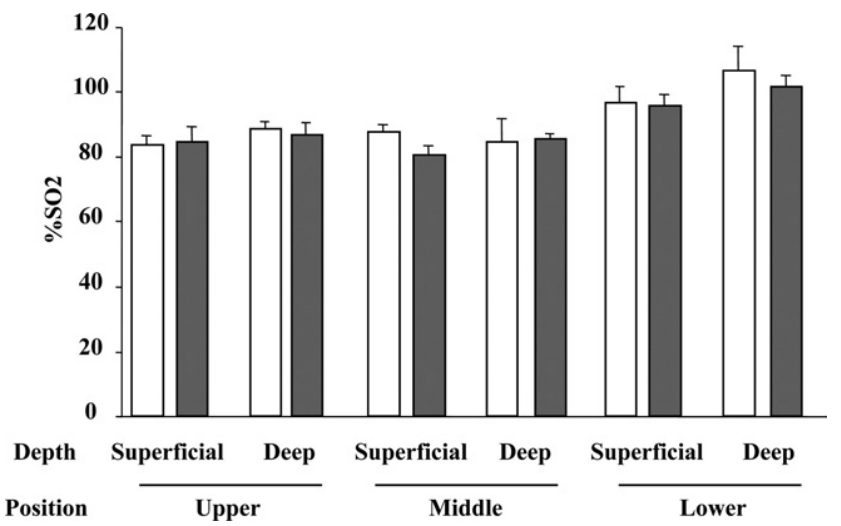

Figure 2. Tissue oxygen saturation (SO2) of the sternum at the presternal side. White column, Group 1 (skeletonized); gray column, group 2 (pedicled). model and demonstrated that skeletonized and semiskeletonized ITA-harvesting techniques caused a similar acute reduction in sternal perfusion during the early postoperative period, and this effect lasted for at least 5 hours. In human subjects Cohen and coworkers ${ }^{4}$ studied sternal vascularity using single photon emission computed tomography after ITA harvesting in detail. In their randomized study bone single photon emission computed tomography was performed during 4 to 9 days after the operation to evaluate the sternal vascularity. They found that the sternal blood flow decreased only when the LITA was harvested as a pedicle and that it was maintained with the skeletonized harvesting.

In short, the greatest limitation of previous studies is that the human sternal microcirculation in the perioperative phase has remained unclear, especially from the aspect of

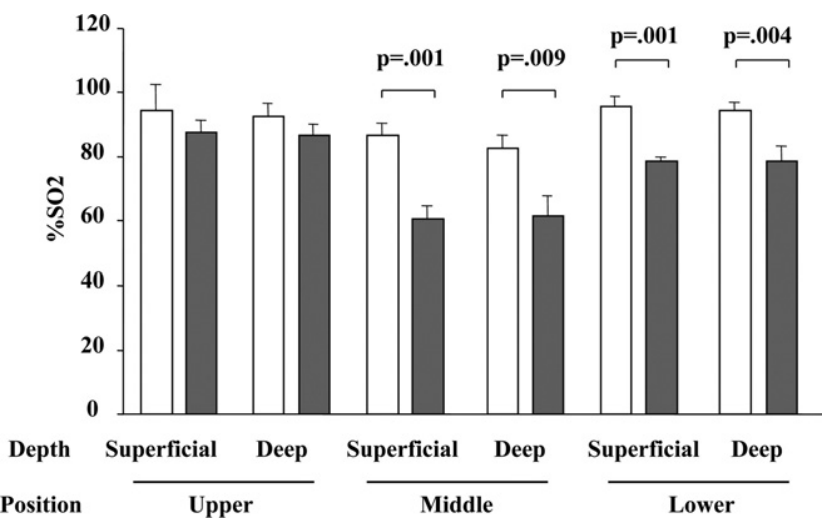

Figure 3. Tissue oxygen saturation (SO2) of the sternum at the retrosternal side. White column, Group 1 (skeletonized); gray column, group 2 (pedicled). 
TABLE 4. Blood flow

\begin{tabular}{|c|c|c|c|c|c|c|}
\hline & \multicolumn{3}{|c|}{ Group 1 (skeletonized) } & \multicolumn{3}{|c|}{ Group 2 (pedicle) } \\
\hline & $\begin{array}{c}\text { Before } \\
\text { harvesting }\end{array}$ & $\begin{array}{c}\text { After } \\
\text { harvesting }\end{array}$ & $P$ value & $\begin{array}{c}\text { Before } \\
\text { harvesting }\end{array}$ & $\begin{array}{c}\text { After } \\
\text { harvesting }\end{array}$ & $P$ value \\
\hline \multicolumn{7}{|l|}{ Presternal } \\
\hline Upper sternal part, 2 mm & $151 \pm 21$ & $62 \pm 5.8$ & .002 & $132 \pm 10$ & $60 \pm 4.4$ & .001 \\
\hline Upper sternal part, 8 mm & $174 \pm 29$ & $105 \pm 16$ & .026 & $190 \pm 21$ & $92 \pm 9.0$ & .001 \\
\hline Middle sternal part, $2 \mathrm{~mm}$ & $149 \pm 10$ & $71 \pm 10$ & .001 & $124 \pm 12$ & $73 \pm 7.7$ & .007 \\
\hline Middle sternal part, $8 \mathrm{~mm}$ & $215 \pm 18$ & $69 \pm 8.9$ & .001 & $169 \pm 20$ & $65 \pm 5.6$ & .001 \\
\hline Lower sternal part, 2 mm & $151 \pm 13$ & $82 \pm 3.8$ & .001 & $172 \pm 10$ & $79 \pm 4.0$ & .001 \\
\hline Lower sternal part, 8 mm & $213 \pm 21$ & $109 \pm 9.0$ & .003 & $225 \pm 32$ & $104 \pm 7.6$ & .003 \\
\hline \multicolumn{7}{|l|}{ Retrosternal } \\
\hline Upper sternal part, 2 mm & $243 \pm 22$ & $92 \pm 9.0$ & .001 & $284 \pm 26$ & $79 \pm 5.0$ & .001 \\
\hline Upper sternal part, 8 mm & $310 \pm 30$ & $136 \pm 19$ & .001 & $263 \pm 37$ & $122 \pm 12$ & .005 \\
\hline Middle sternal part, $2 \mathrm{~mm}$ & $200 \pm 17$ & $152 \pm 16$ & .038 & $231 \pm 16$ & $93 \pm 6.0$ & .001 \\
\hline Middle sternal part, $8 \mathrm{~mm}$ & $239 \pm 20$ & $146 \pm 11$ & .002 & $256 \pm 26$ & $102 \pm 5.4$ & .001 \\
\hline Lower sternal part, 2 mm & $172 \pm 9$ & $90 \pm 5.1$ & .001 & $178 \pm 12$ & $69 \pm 8.2$ & .001 \\
\hline Lower sternal part, 8 mm & $205 \pm 26$ & $125 \pm 9$ & .017 & $215 \pm 22$ & $98 \pm 10$ & .001 \\
\hline
\end{tabular}

Data of blood flow are presented as means \pm standard error of the mean.

tissue oxygenation. Generally, wound healing is possible only through restoration of the microcirculation and the nutrition to the tissue, and because the main component of the nutrition is oxygen, local hypoxia results in delayed healing and increased risk of infection. ${ }^{15}$ To our knowledge, the present study is the first to demonstrate the sternal microcirculation including the tissue oxygenation in the acute phase after ITA harvesting in regard to skeletonized technique.

Interestingly, some discrepancies between the decrease of the tissue $\mathrm{SO}_{2}$ and of the blood flow were observed in the present study. Although blood flow decreased at almost all measurement points with both techniques, the tissue $\mathrm{So}_{2}$ did not decrease at the lower sternum on the presternal side with either technique, and the decrease of tissue $\mathrm{So}_{2}$ at the lower

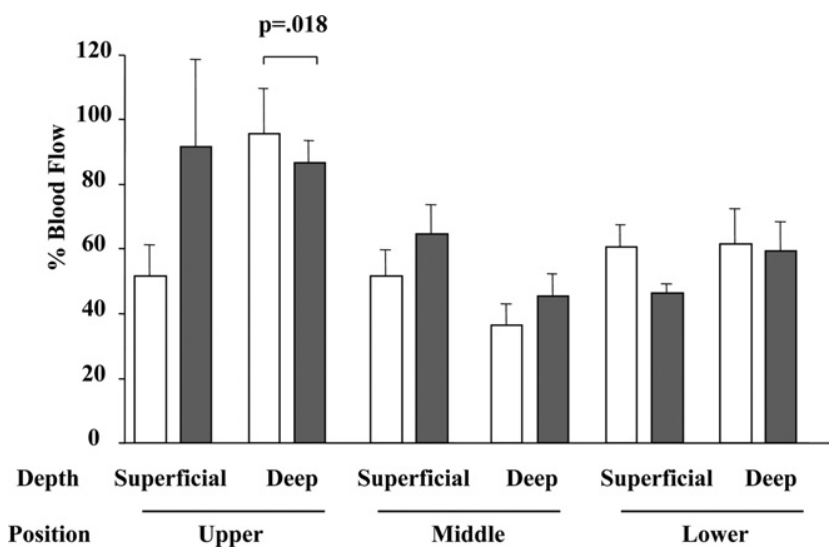

Figure 4. Blood flow of the sternum at the presternal side. White column, Group 1 (skeletonized); gray column, group 2 (pedicled). sternum on the retrosternal side was not significant with the skeletonized technique, as shown in Tables 3 and 4. These findings might have resulted from the collateral flow from the inferior epigastric artery. However, the clinical implications of these discrepancies remain unclear.

One of the major findings in the present study was that skeletonization had no advantage in preserving the presternal microcirculation, whereas the deterioration of the retrosternal microcirculation was significantly less with the skeletonized technique. This finding fits with published risk factor analyses, except for showing slightly distinct risk factors for superficial and deep sternal wound infections. ${ }^{12,16}$ Pevni and colleagues ${ }^{16}$ demonstrated that the use of the skeletonized bilateral ITA was predictive for deep, but not superficial, sternal wound infections, whereas obesity and an age of greater than 75 years were mainly

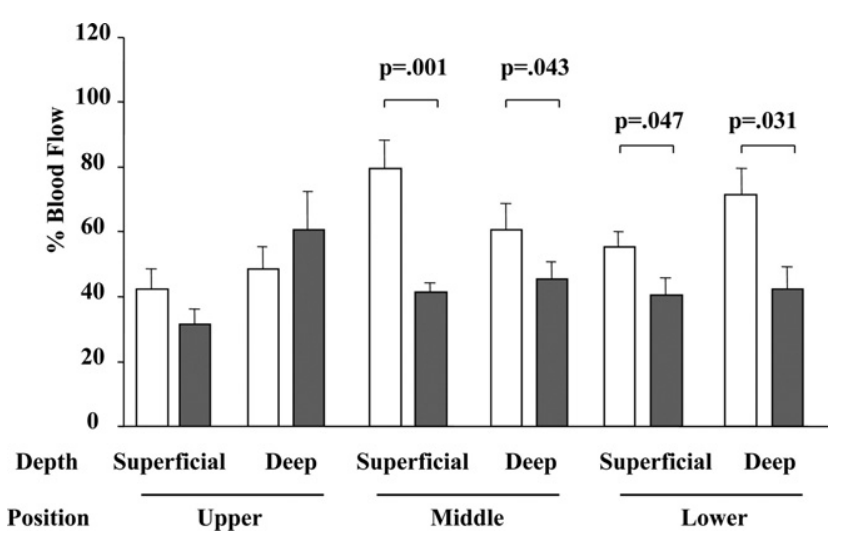

Figure 5. Blood flow of the sternum at the retrosternal side. White column, Group 1 (skeletonized); gray column, group 2 (pedicled). 
predictive for superficial sternal infections. De Paulis and associates $^{12}$ analyzed the effect of bilateral ITA harvesting on superficial and deep sternal infections, and they found a slightly lower odds ratio for superficial sternal infection than for deep sternal infection. The technique of artery harvesting was an independent predictor for deep sternal infection, with an odds ratio of 4.1 (95\% confidence interval, 1.4-12.1), whereas it was an independent predictor of superficial sternal infection, with an odds ratio of 3.0 (95\% confidence interval, 1.6-5.4). The findings of our present study and the clinical results of previous relative large studies suggest that skeletonized ITA harvesting can reduce the risk of deep sternal infection.

In conclusion, skeletonization had no advantage in maintaining presternal microcirculation, whereas the deterioration of the retrosternal microcirculation was significantly less when the skeletonized technique was used. Although there was no clinical difference in infection rates between study groups because of the small study cohort, our results might suggest that the skeletonized ITA harvesting can reduce the risk of deep sternal infection.

\section{References}

1. El OR, Paul E, Wong PS, et al. Mediastinitis in patients undergoing cardiopulmonary bypass: risk analysis and midterm results. J Cardiovasc Surg (Torino). 1997;38:595-600.

2. Kohli M, Yuan L, Escobar M, et al. A risk index for sternal surgical wound infection after cardiovascular surgery. Infect Control Hosp Epidemiol. 2003;24:17-25.

3. Grossi EA, Esposito R, Harris LJ, et al. Sternal wound infections and use of internal mammary artery grafts. J Thorac Cardiovasc Surg. 1991;102:342-6.
4. Cohen AJ, Lockman J, Lorberboym M, et al. Assessment of sternal vascularity with single photon emission computed tomography after harvesting of the internal thoracic artery. J Thorac Cardiovasc Surg. 1999;118:496-502.

5. Lorberboym M, Medalion B, Bder O, et al. 99mTc-MDP bone SPECT for the evaluation of sternal ischaemia following internal mammary artery dissection. Nucl Med Commun. 2002;23:47-52.

6. Parish MA, Asai T, Grossi EA, et al. The effects of different techniques of internal mammary artery harvesting on sternal blood flow. J Thorac Cardiovasc Surg. 1992;104:1303-7.

7. Knobloch K, Lichtenberg A, Pichlmaier M, et al. Microcirculation of the sternum following harvesting of the left internal mammary artery. Thorac Cardiovasc Surg. 2003;51:255-9.

8. Knobloch K, Lichtenberg A, Pichlmaier M, Tomaszek S, Krug A, Haverich A. Palmar microcirculation after harvesting of the radial artery in coronary revascularization. Ann Thorac Surg. 2005;79:1026-30.

9. Boylan MJ, Lytle BW, Loop FD, et al. Surgical treatment of isolated left anterior descending coronary stenosis. Comparison of left internal mammary artery and venous autograft at 18 to 20 years of follow-up. J Thorac Cardiovasc Surg. 1994;107:657-62.

10. Lytle BW, Blackstone EH, Loop FD, et al. Two internal thoracic artery grafts are better than one. J Thorac Cardiovasc Surg. 1999;117:855-72.

11. Peterson MD, Borger MA, Rao V, Peniston CM, Feindel CM. Skeletonization of bilateral internal thoracic artery grafts lowers the risk of sternal infection in patients with diabetes. $J$ Thorac Cardiovasc Surg. 2003;126:1314-9.

12. De Paulis R, de Notaris S, Scaffa R, et al. The effect of bilateral internal thoracic artery harvesting on superficial and deep sternal infection: the role of skeletonization. J Thorac Cardiovasc Surg. 2005;129:536-43.

13. Bical OM, Khoury W, Fromes Y, et al. Routine use of bilateral skeletonized internal thoracic artery grafts in middle-aged diabetic patients. Ann Thorac Surg. 2004;78:2050-3.

14. Fokin AA, Robicsek F, Fokin A Jr, Anderson JE Jr. Changes in sternal blood flow after different methods of internal thoracic artery harvesting. Thorac Cardiovasc Surg. 2004;52:334-7.

15. Gottrup F. Oxygen in wound healing and infection. World J Surg. 2004;28:312-5.

16. Pevni D, Mohr R, Lev-Run O, Locer C, Paz Y, Kramer A, Shapira I. Influence of bilateral skeletonized harvesting on occurrence of deep sternal wound infection in 1000 consecutive patients undergoing bilateral internal thoracic artery grafting. Ann Surg. 2003;237:277-80. 